\title{
The influencing factors of absenteeism among nursing students
}

\author{
Safaa M. Abdelrahman ${ }^{* 1}$, Abeer M. Abdelkader ${ }^{2}$ \\ ${ }^{1}$ Nursing Administration Department, Faculty of Nursing, Minia University, Minia, Egypt \\ ${ }^{2}$ Nursing Education Department, Faculty of Nursing, Minia University, Minia, Egypt
}

Received: January 5, 2017

DOI: $10.5430 /$ jnep.v7n10p64
Accepted: February 26, $2017 \quad$ Online Published: May 14, 2017

URL: https://doi.org/10.5430/jnep.v7n10p64

\begin{abstract}
The absence of nursing students from classrooms and clinical has a negative impact on their performance and prolongs the length of their studying. The aim of this study is to identify the influencing factors of absenteeism among nursing students at Minia University. This study was conducted at the Faculty of Nursing at Minia University, and Minia University Hospitals. The sample of students that participated in the study represented all academic levels as follows: first level 49/370, second level 49/292, third level 52/248, and fourth level 50/220. Data were collected with the use of a self-administered questionnaire. This study revealed that influencing factors of absenteeism among the studied nursing students indicated that the highest mean scores were associated with teaching factors, followed by assessment factor where means scores were (18.3 \pm 4.5 , and $17.1 \pm 5.6$, respectively). Also, the lowest mean score reported was associated with social problems (mean $=8.9 \pm 3.2$ ). This study concluded that the most common contributory factors in student absenteeism were related to teaching factors including a shortage of staff in the clinical area, and lack of understanding of the lecture content. Recommendations: Providing a safe learning environment, keeping accurate records of attendance and calculating absenteeism rates at frequent intervals are required for identifying each individual's pattern of attendance.
\end{abstract}

Key Words: Absenteeism factors, Nursing students, Learning environment

\section{INTRODUCTION}

Absenteeism refers to a situation where the learner is not available in the faculty for an entire day. ${ }^{[1]}$ Absenteeism increases when a nursing student does not attend in classroom and clinical learning area due to the lack of suitable resources, shortage of academic staff, equipment in the areas of practical training in hospitals, as well as insufficient lab numbers, and low ratio of patients to students. So, the students don't have enough training and practice and increase their absenteeism rate.

Nursing students' absenteeism from classrooms and clini- cal settings has a negative impact on their performance and their study length. ${ }^{[2]}$ Nursing education for enrollment by the SANC as a nurse or auxiliary complies with the requirements of formal tertiary education. A nursing college or other institutions approved as a nursing collage by the SANC in terms of the Act provide tertiary education. It is, also, provided with the view to the acquisition of a certificate instituted in terms of the SANC. ${ }^{[3]}$

The study was conducted at the College of Nursing, Minia University, and indicated that the shortage of clinical nursing staff may play a significant role in students' absenteeism

*Correspondence: Safaa M. Abdelrahman; Email: abdelrahman.safaa@yahoo.com; Address: Nursing Administration Department, Faculty of Nursing, Minia University, Minia 61511, Egypt. 
during their education and training. The clinical manager and the acting matron reported that the shortage of hospital staff is challenging for clinical teaching, which is why tutors were asked to be present during students clinical training, in order to support them. ${ }^{[4]}$

The Department of Health and Social Development ${ }^{[5]}$ indicated that students are likely to be absent from clinical and classroom settings due to fear of contracting communicable diseases found in the wards or if they are already infected.

Nursing students were allocated in a clinical learning setting to acquire clinical skills. The clinical rapport between lecturers and clinical staff may result in some learners avoiding their allocated wards. Lecturers who removed the learners from their allocated wards without notifying the managers within the allocated clinical settings were said to increase the problem of absenteeism. However, through the experience of being in the hospital that was utilized as a clinical facility for student nurses, it was observed that some nursing students usually disappear from the clinical setting without the knowledge of their supervisor. ${ }^{[6]}$

A number of factors, such as lack of interest and unchallenging curriculum cause absenteeism. A desire for hedonistic activities with peers, negative self-image and self-esteem, lack of subject interest, lack of personal interest in studies, the mental capacity of a student that does not match with the course update, and lecturers' poor teaching skills may also keep students away from their study. Likewise, lack of confidence in a lecturer, inadequate relationships between students and lecturer, and the travelling distance to nurs- ing schools, colleges and universities could lead to student absenteeism. ${ }^{[7]}$

\subsection{Significance of the study}

Students' aabsenteeism from classrooms and clinical settings seems to have a negative impact on the quality of teaching, learning and assessment. Some demonstrators in hospitals reported that nursing students were absent from clinical settings on a weekly basis. Clinical instructors and hospital nurse managers also reported that some nursing students sign the logbook in the morning shift for the next day when they plan not to attend classes. Professional nurses at the clinics expressed concerns that sometimes, in clinical settings, nursing forge fellow students' signature and sign on their behalf. ${ }^{[5]}$

From the perspective of the researcher, the Vice Dean for Education and Student Affairs, in the College of Nursing at Minia University, reported that on the first semester, six students from the first, six from the second year, and twelve from the final year were not allowed to participate in final exams, as a result of their poor attendance record. Also, ultimatums were given to eight second-year students who were not also not allowed to attend their final exam in the second semester of the academic year 2015-2016. It was observed that $50 \%$ of students fail to attend all the theoretical lessons in the College of Nursing at Minia University. So, it was deemed necessary to conduct the present study in order to identify the reasons behind nursing students' absentieesm from lectures, hospital labs and similar clinical settings (see Figure 1).

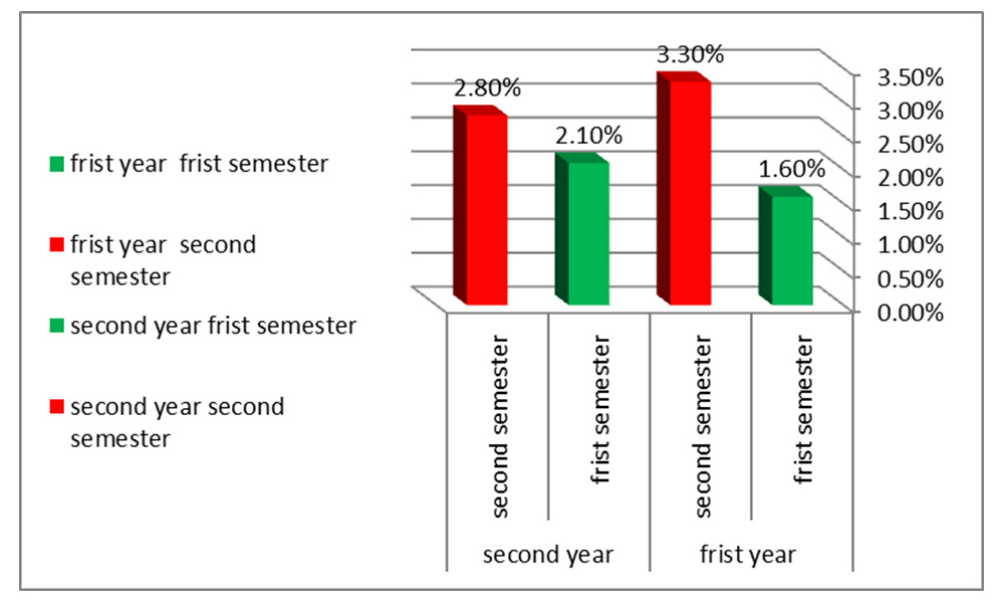

Figure 1. Representative to all nursing students in the college not limited to the study sample

\subsection{Aim of the study}

To identify the influencing factors of absenteeism among nursing students at Minia University.

Published by Sciedu Press

\section{SUBJECTS AND METHODS}

\subsection{Research design}

A descriptive cross-sectional design was used to identify the factors that contributed to the absenteeism of nursing 
students at Minia University.

\subsection{Research question}

What are the factors that led to the absence of nursing students at Minia University?

\subsection{Setting}

This study was conducted at the College of Nursing and Minia University Hospitals.

\subsection{Subjects}

Participants consisted of 200 out of the total of 1,130 nursing students, who were enrolled at the College of Nursing at Minia University in the 2015-2016 academic years. The enrolled students were representative of all academic levels as follows: first level 49/370 (13.3\%), second level 49/292 (16.8\%), third level 52/248 (21.6\%), and fourth level 50/220 $(22.7 \%)$.

\subsection{Sampling}

The representative sample consisted of students from all four academic years in the College of Nursing. The number of the students selected from each academic year depended on the total number of students registered in that year.

\subsection{Tool and method of data collection}

\subsubsection{Tool}

A self-administered questionnaire developed by Thobakgale $(2013)^{[8]}$ was used to collect data from the study subjects. It took about 25-30 minutes for most of the enrollees to fill in the form. Questions about the factors affecting absenteeism were divided into two parts: the first part included questions related to social-demographic data of the study subjects, e.g., age, sex and academic level. The second part consisted of questions relevant to the reasons contributing to absence of nursing students. The questionnaire was developed by Thobakgale (2013) ${ }^{[8]}$ and this tool is an international standardized tool and it was slightly modified by the researcher. It consisted of 23 items grouped into five sections, namely, teaching (6 items), course content (4 items), learning (4 items), assessment (6 items) and social problems (3 items). Scoring system: the instrument uses a five point Likert scale ranging from "strongly agree to strongly disagree". These are scored from 1 to 5 , respectively.

\subsubsection{Method}

Permission to conduct the study was obtained from all responsible authorities at the College of nursing at Minia University (the Dean and heads of departments) after explaining the purpose of the study.

Reliability was measured by doing a Cronbach's Alpha, its value was 0.97 . Ten questionnaires were distributed to stu- dent nurses. The respondents were not included in the main study. This pilot study was carried out to investigate the feasibility of the proposed study and to detect possible flaws in the data collection instruments such as ambiguous instructions or wording, inadequate time limits.

Validity of the tool was tested by consultation of Specialist nurses in nursing education and management to evaluate the applicability and content validity. Specialists reviewed the objectives of the study and questionnaire decided on the appropriateness of the questionnaire items. The specialists examined each item and make judgments whether the degree to which the questionnaire appears to measure a concept by a logical analysis of the items.

A pilot study was carried out on a sample of ten participants to check and ensure the clarity and applicability of the tools. Based on the findings, corrections were done when necessary. The pilot participants were not included in the main study subjects.

Data were collected between 1st November 2015 and 31st May 2016.

\subsection{Ethical considerations}

An approval from the research committee was obtained prior to conducting the study. Also, ethical issues in this study included assurance of confidentiality and anonymity of the participants and their responses. In addition, all participants were informed with the study purpose and that their participation was strictly voluntary.

\subsection{Statistical analysis}

After the data were collected, they were revised, coded and fed to the statistical software SPSS version 20. The given graphs were constructed using Microsoft Excel Software. Add statistical tests for data analysis as mean, standard deviation and used the comparisons between groups of variables were done with ANOVA Test. The $p$ value of $<.05$ indicated statistical significance.

\section{RESULTS}

Table 1 shows the distribution of the gender and age of the participating nursing students. $63 \%$ of the respondents were females and the highest percent $(86.5 \%)$ of them were $19-25$ years old. Regarding the respondents educational level, there were $26 \%$ of the third grade, with the highest percentage of classroom attendance in the College of Nursing being (45\%).

Table 2 shows the description of the study sample regarding the absenteeism reasons related to teaching. The highest percentage $(52.5 \%)$ of the nursing students agreed that the resources for procedures are not available. Also, $38.5 \%$ of 
them disagreed that the lecturer daily questions were not the a reason for their absence. On the other hand, $32.5 \%$ of the reason. It was found that $39 \%$ of the students disagreed that students disagreed that a boring subject was the reason for they do not understand the language used by the lecturer as their absence.

Table 1. Socio-demographic characteristics of the study subjects $($ No $=200)$

\begin{tabular}{|c|c|c|c|}
\hline Variables & & No & $\%$ \\
\hline \multirow{2}{*}{ Gender } & Male & 74 & 37 \\
\hline & Female & 126 & 63 \\
\hline \multirow{3}{*}{ Age } & $<19$ & 27 & 13.5 \\
\hline & $19-25$ & 173 & 86.5 \\
\hline & Mean \pm SD & $1.9 \pm 34$ & \\
\hline \multirow[t]{4}{*}{ Academic Level } & First & 49 & 24.5 \\
\hline & Second & 49 & 24.5 \\
\hline & Third & 52 & 26 \\
\hline & Fourth & 50 & 25 \\
\hline \multirow{4}{*}{ Educational settings } & Minia University Hospitals & 40 & 20 \\
\hline & Obstetric and Children hospital & 11 & 5.5 \\
\hline & College of Nursing in classroom & 90 & 45 \\
\hline & College of nursing labs & 59 & 29.5 \\
\hline Total & & 100 & 100 \\
\hline
\end{tabular}

Table 2. Distribution of the study sample about absenteeism reasons related to teaching factor $($ No $=200)$

\begin{tabular}{|c|c|c|c|c|c|c|c|c|c|c|}
\hline \multirow{2}{*}{ Teaching } & \multicolumn{2}{|l|}{ SD } & \multicolumn{2}{|l|}{ D } & \multicolumn{2}{|l|}{$\mathbf{U N}$} & \multicolumn{2}{|l|}{ A } & \multicolumn{2}{|l|}{ SA } \\
\hline & No & $\%$ & No & $\%$ & No & $\%$ & No & $\%$ & No & $\%$ \\
\hline Resources for procedures are not available & 22 & 11 & 36 & 18 & 16 & 8 & 105 & 52.5 & 21 & 10.5 \\
\hline I feel that certain subjects are forced against my will & 27 & 13.5 & 51 & 25.5 & 21 & 10.5 & 65 & 32.5 & 36 & 18 \\
\hline If my lecturer asks me many questions every day & 29 & 14.5 & 77 & 38.5 & 18 & 9 & 51 & 25.5 & 25 & 12.5 \\
\hline Shortage of staff in the clinical area & 55 & 27.5 & 39 & 19.5 & 21 & 10.5 & 38 & 19 & 47 & 23.5 \\
\hline I do not understand the language used by the lecturer & 33 & 16.5 & 78 & 39 & 18 & 9 & 39 & 19.5 & 32 & 16 \\
\hline A boring subject & 20 & 10 & 65 & 32.5 & 13 & 6.5 & 62 & 31 & 40 & 20 \\
\hline
\end{tabular}

Note. $\mathrm{SD}$ = strong disagree, $\mathrm{D}=$ disagree, $\mathrm{UN}$ = uncertain, $\mathrm{A}$ = agree, $\mathrm{SA}$ = strong agree.

Table 3 shows the response of the study participants regard- respectively. On the other hand, the lowest percentage (8\%) ing absenteeism reasons related to the content. As shown, of the participants strongly disagreed that work overloading $46 \%$, and $46.5 \%$ of nursing student agree that if "I am not in the clinical area was the reason. However, there were high explaining the importance of attending full hours as training percentages (38\%) of the nursing students agreeing that the requirements" and "I do not want to be treated as workforce", course outline was not clear.

Table 3. Distribution of the study sample about absenteeism reasons related to content factor $($ No $=200)$

\begin{tabular}{|c|c|c|c|c|c|c|c|c|c|c|}
\hline \multirow{2}{*}{ Content } & \multicolumn{2}{|l|}{ SD } & \multicolumn{2}{|l|}{ D } & \multicolumn{2}{|c|}{ UN } & \multicolumn{2}{|l|}{ A } & \multicolumn{2}{|l|}{ SA } \\
\hline & No & $\%$ & No & $\%$ & No & $\%$ & No & $\%$ & No & $\%$ \\
\hline $\begin{array}{l}\text { If I have not explained the importance of } \\
\text { attending full hours as training requirements }\end{array}$ & 37 & 18.5 & 39 & 19.5 & 10 & 5 & 92 & 46 & 22 & 11 \\
\hline The course outline is no clear to me & 30 & 15 & 41 & 20.5 & 43 & 21.5 & 76 & 38 & 10 & 5 \\
\hline Work overload in the clinical area & 16 & 8 & 36 & 18 & 16 & 8 & 81 & 40.5 & 51 & 25.5 \\
\hline I do not want to be treated as workforce & 24 & 12 & 40 & 20 & 19 & 9.5 & 93 & 46.5 & 24 & 12 \\
\hline
\end{tabular}

Note. $\mathrm{SD}=$ strong disagree, $\mathrm{D}=$ disagree, $\mathrm{UN}=$ uncertain, $\mathrm{A}=$ agree, $\mathrm{SA}=$ strong agree 
Table 4 shows that the percentage distribution of the study sentations" as reasons for their absence, respectively. There sample regarding absenteeism reasons related to learning. were $31.5 \%$ and $39.5 \%$ of the nursing students strongly disThere were high percentages (34\% and 38\%) of the nursing students agreeing that "because of poor discipline from College of Nursing" and "If I am late during the lesson preagreeing that "when I am lazy doing the work" and "when lecturers are absent" as reasons for their absence, respectively.

Table 4. Distribution of the study sample about absenteeism reasons related to learning factor $(\mathrm{No}=200)$

\begin{tabular}{|c|c|c|c|c|c|c|c|c|c|c|}
\hline \multirow{2}{*}{ Learning } & \multicolumn{2}{|l|}{ SD } & \multicolumn{2}{|l|}{ D } & \multicolumn{2}{|l|}{ UN } & \multicolumn{2}{|l|}{ A } & \multicolumn{2}{|l|}{ SA } \\
\hline & No & $\%$ & No & $\%$ & No & $\%$ & No & $\%$ & No & $\%$ \\
\hline Because of poor discipline from College of nursing & 30 & 15 & 54 & 27 & 17 & 8.5 & 68 & 34 & 31 & 15.5 \\
\hline When I am lazy doing the work & 63 & 31.5 & 60 & 30 & 26 & 13 & 25 & 12.5 & 26 & 13 \\
\hline If I am late during lesson presentations & 37 & 18.5 & 49 & 24.5 & 22 & 11 & 76 & 38 & 16 & 8 \\
\hline When lecturers are absent & 79 & 39.5 & 66 & 33 & 13 & 6.5 & 31 & 15.5 & 11 & 5.5 \\
\hline
\end{tabular}

Note. $\mathrm{SD}=$ strong disagree, $\mathrm{D}=$ disagree, $\mathrm{UN}=$ uncertain, $\mathrm{A}=$ agree, $\mathrm{SA}=$ strong agree.

Table 5 shows the response of the study sample regarding absenteeism reasons related to assessment. It was found that $29.5 \%$ of the nursing students disagreed that "when I am supposed to demonstrate the procedure" and the lowest percentage $(7 \%)$ of them strongly agreed that "I do not want to do presentations" as reasons for their absence. It was found that $(28.5 \%, 40.5 \%, 39.5$ and $24.5 \%)$ of the nursing student agreed to "Poor performance in the classroom", "When I am not ready to write the examination", "When I am not ready to do feedback evaluation" and "On Objective Structured Clinical Evaluation (OSCE) day" as reasons for their absence, respectively.

Table 5. Percent distribution of the study sample about absenteeism reasons related to assessment factor

\begin{tabular}{|c|c|c|c|c|c|c|c|c|c|c|}
\hline \multirow{2}{*}{ Assessment } & \multicolumn{2}{|l|}{ SD } & \multicolumn{2}{|l|}{$\mathbf{D}$} & \multicolumn{2}{|l|}{ UN } & \multicolumn{2}{|l|}{$\bar{A}$} & \multicolumn{2}{|l|}{ SA } \\
\hline & No & $\%$ & No & $\%$ & No & $\%$ & No & $\%$ & No & $\%$ \\
\hline When I am supposed to demonstrate the procedure & 57 & 28.5 & 59 & 29.5 & 11 & 5.5 & 57 & 28.5 & 16 & 8 \\
\hline I do not want to do presentations & 54 & 27 & 49 & 24.5 & 21 & 10.5 & 62 & 31 & 14 & 7 \\
\hline Poor performance in classroom & 34 & 17 & 50 & 24.5 & 11 & 5.5 & 57 & 28.5 & 48 & 24 \\
\hline When I am not ready to write the examination & 36 & 18 & 43 & 21.5 & 15 & 7.5 & 81 & 40.5 & 25 & 12.5 \\
\hline When I am not ready doing feedback evaluation & 32 & 16 & 48 & 24 & 17 & 8.5 & 79 & 39.5 & 24 & 12 \\
\hline $\begin{array}{l}\text { On Objective Structured Clinical Evaluation } \\
\text { (OSCE) day }\end{array}$ & 48 & 24 & 47 & 23.5 & 22 & 11 & 49 & 24.5 & 34 & 17 \\
\hline
\end{tabular}

Note. $\mathrm{SD}$ = strong disagree, $\mathrm{D}=$ disagree, $\mathrm{UN}$ = Uncertain, $\mathrm{A}$ = agree, $\mathrm{SA}=$ strong agree

Table 6 presents the distribution of the study subjects regard- absence. Also, the highest percentages (39\% and 36\%) of ing absenteeism reasons related to social problems. It shows the students agreed that "on family responsibility leave" and that $28 \%$ of the nursing students have strong disagreement "I must solve my family problem" were the reasons for their that "attending community activities" is the reason for their absence, respectively.

Table 6. Percent distribution of the study sample about absenteeism reasons related to social problems factor

\begin{tabular}{|c|c|c|c|c|c|c|c|c|c|c|}
\hline \multirow{2}{*}{ Items } & \multicolumn{2}{|l|}{ SD } & \multicolumn{2}{|l|}{ D } & \multicolumn{2}{|l|}{ UN } & \multicolumn{2}{|l|}{ A } & \multicolumn{2}{|l|}{ SA } \\
\hline & No & $\%$ & No & $\%$ & No & $\%$ & No & $\%$ & No & $\%$ \\
\hline Attend community activities & 56 & 28 & 56 & 28 & 27 & 13.5 & 37 & 18.5 & 24 & 12 \\
\hline On family responsibility leave & 28 & 14 & 51 & 25.5 & 26 & 13 & 78 & 39 & 17 & 8.5 \\
\hline I must solve my family problem & 24 & 12 & 51 & 25.5 & 18 & 9 & 72 & 36 & 35 & 17.5 \\
\hline
\end{tabular}

Note. $\mathrm{SD}=$ strong disagree, $\mathrm{D}=$ disagree, $\mathrm{UN}=$ Uncertain, $\mathrm{A}$ = agree, $\mathrm{SA}=$ strong agree 
Table 7 illustrates that there were statistically significant differences and a positive relationship between gender and all absenteeism factors (Teaching, Content, Learning, and Assessment) ( $p=.000, .001, .04$, and .000 , respectively) except Social Problems $(p=.69)$. Also, statistically significant differences and positive relationships were found between age and all absenteeism factors (Teaching, Content, Assessment, and Social Problems) except Learning factor. In addition, statistically significant differences and a positive relationship were found between academic level and all absenteeism factors (Teaching, Content, Assessment, and Social Problems) except Learning factor. Moreover, the same table indicated statistical significant differences and positive relationship between Academic Setting and Social Problems factor.

Table 7. Relations between General Characteristic of the study sample and the absenteeism factors

\begin{tabular}{|c|c|c|c|c|c|}
\hline \multirow{3}{*}{ General Characteristic } & \multicolumn{5}{|c|}{ Absenteeism factors } \\
\hline & Teaching & Content & Learning & Assessment & Social Problems \\
\hline & Mean \pm SD & Mean \pm SD & Mean \pm SD & Mean \pm SD & Mean \pm SD \\
\hline \multicolumn{6}{|l|}{ Gender } \\
\hline Male & $20 \pm 5.2$ & $13.9 \pm 3.5$ & $11.8 \pm 3.4$ & $20.3 \pm 4.8$ & $8.8 \pm 2.3$ \\
\hline Female & $17.1 \pm 4.8$ & $12.3 \pm 3.4$ & $10.3 \pm 5.5$ & $15.9 \pm 5.5$ & $.9 \pm 3.5$ \\
\hline F Test & 16.8 & 10.5 & 10.8 & 35.1 & 0.15 \\
\hline$p$ & .000 & .001 & .04 & .000 & .69 \\
\hline \multicolumn{6}{|l|}{ Age } \\
\hline$<19$ & $16.6 \pm 5.5$ & $11.6 \pm 3.5$ & $9.9 \pm 3.02$ & $15.8 \pm 5.7$ & $10.7 \pm 2.6$ \\
\hline $19-25$ & $18.5 \pm 5.1$ & $13.1 \pm 3.4$ & $11.1 \pm 5.1$ & $17.8 \pm 5.6$ & $8.6 \pm 3.3$ \\
\hline F Test & 3.4 & 4.1 & 1.1 & 2.6 & 11 \\
\hline$p$ & .06 & .04 & .29 & .001 & .001 \\
\hline \multicolumn{6}{|l|}{ Academic Level } \\
\hline First & $17.3 \pm 5.7$ & $11.6 \pm 3.5$ & $16.5 \pm 6.2$ & $10.1 \pm 3.3$ & $10.4 \pm 3.3$ \\
\hline Second & $19.4 \pm 4$ & $13.2 \pm 2.8$ & $19.1 \pm 4.3$ & $11.8 \pm 3.2$ & $7.3 \pm 2.4$ \\
\hline Third & $19.4 \pm 5.3$ & $13.9 \pm 3.5$ & $19 \pm 5.1$ & $10.1 \pm 3.1$ & $9.5 \pm 3.0$ \\
\hline Fourth & $16.7 \pm 4.6$ & $11.4 \pm 8.1$ & $15.4 \pm 5.9$ & $11.4 \pm 8.1$ & $7.6 \pm 3.4$ \\
\hline F Test & 4.1 & 4.3 & 1.5 & 5.9 & 9.2 \\
\hline$p$ & .008 & .006 & .20 & .001 & .000 \\
\hline \multicolumn{6}{|l|}{ Academic Setting } \\
\hline Minia University Hospitals & $18.1 \pm 5.1$ & $12.6 \pm 3.6$ & $11.2 \pm 3.6$ & $17.9 \pm 4.6$ & $8.6 \pm 3.1$ \\
\hline Obstetric and child hospitals & $19.9 \pm 4.6$ & $13.9 \pm 3.5$ & $10.1 \pm 2.6$ & $17.8 \pm 5.4$ & $10.0 \pm 3.9$ \\
\hline College of nursing in classroom & $17.9 \pm 5.5$ & $13.2 \pm 3.5$ & $11.5 \pm 6.4$ & $17.4 \pm 6.1$ & $8.1 \pm 3.1$ \\
\hline College of nursing lab. & $18.3 \pm 4.6$ & $12.4 \pm 3.3$ & $9.7 \pm 2.6$ & $17.1 \pm 5.6$ & $8.9 \pm 3.2$ \\
\hline F Test & 0.80 & 1.3 & 1.26 & 0.55 & 4.3 \\
\hline$p$ & .52 & .26 & .29 & .69 & .003 \\
\hline
\end{tabular}

\section{Discussion}

Student absenteeism is a major concern for university education worldwide. ${ }^{[9]}$ In college settings, students experience their first encounter with theoretical lectures in lecture halls or large classrooms and attendance is not always mandatory. In contrast, practical classes are delivered in small groups of students, and students' attendance is compulsory. Lectures delivered to large groups of students, create difficulties to lecturers and at the same time open the way to absenteeism amongst students. ${ }^{[10]}$

Published by Sciedu Press
Undergraduate nursing students at the college of nursing at Minia University should attend a minimum of $75 \%$ of each course credit hours for all nursing courses. Traditionally, nursing students' attendance was monitored quite closely. Records of attendance at both the classroom and clinical settings were kept and formalized disciplinary procedures were in place to deal with those with excessive absenteeism or absenteeism without due notification. The total number of nursing students at the College of Nursing at Minia University was 1,130 (first year $=375$, second year $=292$, third year $=248$, and fourth year $=220$ ). The College of Nurs- 
ing at Minia University lacked appropriate general building conditions (physical, learning environment recourses such as sufficient classrooms, labs, clinical settings, and educational technology recourses). This study was conducted to identify the factors that contribute to absence of nursing students at Minia University. The study revealed that students reported their absenteeism reasons were related to teaching factor, as shortage of staff in the clinical area and not understanding the lecture content. Educators are the providers and facilitators of essential knowledge, skills, and attitudes required for the progress and future of nurses. ${ }^{[11]}$ This result was in the same line of another. Desalegn and Berhan ${ }^{[9]}$ who stated that the main reasons reported for missing lectures were preparing for another examination, lack of interest, lecturer's teaching style, and availability of lecture material. ${ }^{[9]}$ Also, our findings are in agreement with the another report ${ }^{[12]}$ which showed that the production function for learning in the classroom does require inputs of time from both teachers and students. So, teacher performance and student performance are closely associated ${ }^{[12]}$ In addition, the study results indicated that many nursing students reported that the most common contributory reasons for their absenteeism were related to content factor such as "no explanation about the importance of attending full hours as training requirements, and no clarification of course outlines". This study result was in the line with Bati ${ }^{[10]}$ who identified that the main factors affecting student attendance include mandatories of lectures, whether the lecture notes prepared and materials presented are adequate for the learning process, lecturer-lecture-student quality, the scope and difficulty of the subject, the possibility of learning about the same subject outside lectures, stress, time management and the difficulty of travelling to the university site. ${ }^{[10]}$ Additionally, to ensure academic achievement and future employability, nursing students' attendance during lecture, laboratory and practical sessions are critical and were strongly associated with their achievement. ${ }^{[13]}$

The study results showed that the participating students reported absenteeism reasons related to learning factor as "poor discipline from the Faculty of Nursing, coming late during lesson presentations, I am lazy doing the work, and when the lecturer is absent". This result agrees with Kearney, ${ }^{[14]}$ who indicated that the learning environment is also a key contextual factor for student absenteeism. Learning environment refers to student feelings of connectedness to their college and degree of support a student feels they are provided regarding their academic, social, and other needs. Learning environment and connectedness may also include positive classroom management, participation in extracurricular activities, and tolerant disciplinary procedures. The extent, to which students feel safe, accepted, valued, and respected in their college is a key aspect of college connectedness as well Kearney. ${ }^{[14]}$ In addition, it was reported that those involved with nursing education programs are committed to maintaining a high attendance level and students must receive adequate theoretical and practical instruction in order to maintain high standards of professional nursing practice. ${ }^{[15]}$ Poor school building conditions are also associated with student problematic behaviors such as absenteeism and dropout rate. ${ }^{[16]}$ Additionally, the study results revealed that absenteeism reasons were related to assessment factor as "I am supposed to demonstrate the procedure, I do not want to do presentations, and OSCE day". The study data are in the line with Jones, ${ }^{[17]}$ who suggested that assessments and tests actually decreased motivation and increase the chances for students to fail or leave college early, despite the intent. Moreover, Doyle ${ }^{[15]}$ reported that students also admitted to an increase in absenteeism when assignments are due for submission. ${ }^{[15]}$ Furthermore, Desalegn \& Berhan ${ }^{[12]}$ indicated that the main reasons reported for missing lectures were preparing for another examination, lack of interest, lecturer's teaching style, and availability of lecture material. ${ }^{[9]}$

The study results displayed absenteeism reasons related to Social Problems factor such as "Attend community activities and on family responsibility leave". This result is congruent with the result of Shellenbarger and Hoffman ${ }^{[18]}$ who reported that several students may also have family obligations which place additional demands on their time. Some students have children that require childcare or have aging parents with health problems. In addition, other contextual risk factors have been linked to absenteeism. These factors include many reported conflicts at home and family separation, divorce, child self-care, problematic neighborhoods, and maltreatment. ${ }^{[14]}$ Moreover, it was suggested that risk factors associated with student absenteeism are child-related (e.g. Separation anxiety, physical and fears; academic and verbal difficulties aggression; and academic difficulties), Parent and family-related, Limited or Negative peer relationships; or college environment-related (Positive connection with at least one staff member; negative interactions with staff. ${ }^{[19]}$ This study indicated that the highest mean score of factors contributing to absenteeism, reported by the studied subjects was teaching and assessment $(18.3 \pm 4.5$, and $17.1 \pm 5.6$, respectively). This result agrees with the study conducted by Blândul ${ }^{[20]}$ who stated that boredom in the learning environment and inadequate learning climate are key reasons why many students miss school and eventually drop out. Poor learning climate may be linked to harsh and inflexible disciplinary practices, rigid regulations regarding school reintegration, school curricula not well tailored to a student's individual needs or interests, poor teaching and 
student-teacher relationships, inattention to diversity issues, and inadequate attendance management practices. ${ }^{[20]}$ Also, this study showed that statistically significant differences and a positive relationship were found among demographic characteristics (gender, age, and academic level) and all absenteeism factors. These data agree with Bati ${ }^{[10]}$ who reported that the scores of female students are statistically significantly higher than those of males. In contrast, this result disagrees with the data of Rajbhandary and $\mathrm{Basu}^{[21]}$ who stated that male nurses have less absenteeism than their female counterparts. ${ }^{[21]}$ Additionally, transitioning to late adolescence, thereby experiencing changes in their socioemotional development at the same time that they experience a major change in their learning environment. The transition from the supportive environment of secondary school to the less personal and more competitive environment of higher education comes at a time when students are also in an intense period of self-definition. A higher education climate where the rules and expectations are clearly defined, students feel safe, academic excellence is supported, and communication patterns amongst students, teachers and parents specify mutual respect can provide a developmentally appropriate supportive environment for a higher education level.

It is hoped that as a result of the current study, a helpful step will be taken towards a better understanding of student absenteeism. One such challenge is the monitoring of nursing students' attendance, the nursing profession historically value their ability to ensure the public and professional bodies that nursing students fully engage with educational programs. To ensure academic achievement and future employability, student attendance is critical. Research showed attendance is strongly associated with student achievement. University class sizes and the increased perception of student autonomy can negate against formalized monitoring systems. Although this study was conducted with the participation of nursing students, it can act as a guide for improvements in a number of areas, from the planning of the educational process to the design of effective learning environments and the development of educators. By examining large groups and in greater detail regarding the reasons students fail to attend lectures, educational programs in this field must be strengthened with lectures that will lead students to a sense of professional responsibility, with educational methods and techniques and with the quality of educators and appropriate teaching environments. Last, it is important to strengthen the mentoring system with regard to individual and external factors, which have been implicated as having a substantial influence on students lecture attendance.

\section{Conclusions}

The studied nursing students reported that their highest mean score of factors contributing to absenteeism are teaching and assessment. The most common contributory reasons for student absence were related to teaching factors, including shortage of staff in the clinical settings and having a difficulty in understanding the lecture content. Absenteeism reasons related to the assessment include factor as "I am supposed to demonstrate the procedure", "I do not want to do presentations", and "on OSCE day".

\subsection{Recommendations}

(1) Ensuring a positive learning environment by providing a learning environment where students are safe from harm, harassment, ridicule and negative connotations.

(2) Developing attendance policies that include best practices, communicating attendance policies, ensuring policies are consistently enforced, and conducting attendance policy evaluation.

(3) Keeping accurate records of attendance and calculating absenteeism rates at frequent intervals in order to identify each individual's pattern of attendance.

(4) Study of the relationship between teacher attendance, student attendance, achievement, and behavior.

(5) Study of the relationships between academic building conditions and academic achievement.

\section{CONFLicts OF InTEREST Disclosure}

The authors declare that there is no conflict of interest.

\section{REFERENCES}

[1] Weideman M, Goga S, Lopez D. Learner absenteeism in the South African schooling system. 2007. Available from: http://www. in fo.gov.za/view/DownloadFileAction?id=79522

[2] South African Nursing Council. Minimum requirement for the education and training of pupils leading to enrolment as a nurse. Regulation R2175, as amended. Pretoria. SANC. 1997.

[3] South African Nursing Council. The Nursing Act No 33 of 2005. Pretoria: SANC. 2005.
[4] Government of Nursing Schools in Tanzania. A situational analysis of government nursing schools. 2010. Available from: http://www.go2itech.org/where-we-work/tanzania/dow nloads/Scaling-Up-HRH_Tanz_Nov2010.pdf

[5] Department of Health and social development. Lonsdale clinic: quarterly report. Limpopo Province. 2009.

[6] Maryland State Department of Education. Division of accountability and assessment. Habitual truants. Available from: http: //www.marylandpublicschools .org/NR/rdonlyres/805A7 
BDE-C5E7-4106-81D9D1F4008CCFC8/22121/habtru09.pdf

[7] Williams LL. Student absenteeism and truancy: technologies and interventions to reduce and prevent chronic problems among schoolage children. 2002. Available from: http://chiron.valdosta. edu/are/Litreviews/vol1no1/williams_litr.pdf

[8] Thobakgale LM. Factors contributing to absenteeism an pupil nurses in the nursing schools of Capricorn District, Master thesis disagree, limpopo Province in the Faculty of Health science at the University of Limpopo. 2013. 57-58.

[9] Desalegn A, Berhan Y. Absenteeism among medical and health science undergraduate students at hawassa university, ethiopia. BMC Medical Education. 2014; 81(14): 11. https ://doi .org/10.118 6/1472-6920-14-81

[10] Bati H. Why do students miss lectures? A study of lecture attendance amongst students of health science. Nurse Education Today. 2013; 33(1): 596-601. PMid:22863210 https ://doi.org/10.1016/j . nedt. 2012.07.010

[11] Bayard R. Study of the relationship between teacher absenteeism, teacher attributes, school schedule and student achievement. Florida Atlantic Boca Raton. 2013. 150p.

[12] Banerjeea R. Student and teacher attendance: The role of shared goods in reducing absenteeism. Economics of Education Review. 2012; 31(1): 563- 574. https://doi.org/10.1016/j.econed urev.2012.04.002

[13] Dewey A, Miller CA. Project Addressing Educational Leaders' Awareness of Literature-Based Best Practices in Supporting Student Attendance. Saint Louis University. 2012. 154p.
[14] Kearney A. School absenteeism and school refusal behavior in youth Clinical Psychology Review. 2008; 28(1): 451-471. PMid:17720288 https ://doi.org/10.1016/j.cpr.2007.07.012

[15] Doyle L, Timmins F, Tobin G, et al. An evaluation of an attendance monitoring system for undergraduate nursing students. Nurse Education in Practice. 2008; 8(1): 129-139. PMid:17993291 https: //doi.org/10.1016/j.nepr.2007.09.007

[16] Maxwell L. School building condition, social climate, student attendance and academic achievement: A mediation model. Journal of Environmental Psychology. 2016; 46(1): 206-216. https : //doi.org/10.1016/j.jenvp.2016.04.009

[17] Jones W. A correlational study of student achievement and student attendance. Capella. 2010. 121p.

[18] Shellenbarger T, Hoffman R. Lessons in advising for nursing student success. Teaching and Learning in Nursing. 2016; 11(1): 92-100. https://doi.org/10.1016/j.teln.2016.01.006

[19] Sculles K. Chronic Student Absenteeism: Implications For School Leaders. University of Illinois Urbana-Champaign. 2013. 119p.

[20] Blândul V. Scholar absenteeism - a continues challenge of contemporary education. Procedia - Social and Behavioral Sciences. 2013; 76(1): 917-921. https://doi.org/10.1016/j.sbspro.2 013.04 .231

[21] Rajbhandary S, Basu K. Working conditions of nurses and absenteeism: Is there a relationship? An empirical analysis using National Survey of the Work and Health of Nurses. Health Policy. 2010; 97(1): 152-159. PMid:20493577 https ://doi.org/10.1016/j . healthpol.2010.04.010 